\title{
Efficient removal of naproxen from aqueous solution by highly porous activated carbon produced from Grapetree (Plinia cauliflora) fruit peles
}

Jordana Georgin, Kátia da Boit Martinello, Dison S. P. Franco, Matias S. Netto, Daniel G. A. Piccilli, Edson Luiz Foletto, Luis F. O. Silva, Guilherme Luiz Dotto

\begin{abstract}
In this work, jabuticaba (Plinia cauliflora) fruit peels were pyrolyzed in the presence of zinc chloride to generate a novel porous adsorbent to remove naproxen (NPX) from aqueous solutions. The maximum adsorption capacity of the activated carbon for NPX was $167.03 \mathrm{mg} \mathrm{g}^{-1}$, achieved at $328 \mathrm{~K}$. This remarkable result might be mainly assigned to the pore characteristics, such as high surface area $\left(1033 \mathrm{~m}^{2} \mathrm{~g}^{-1}\right)$ and large pore volume $\left(0.520 \mathrm{~cm}^{3} \mathrm{~g}^{-1}\right)$. The Langmuir model was the one that obtained the best values of statistical coefficients, indicating the occurrence of surface saturation. The adsorption process occurred spontaneously under endothermic conditions. The experimental adsorption kinetics was well described by the linear driving force model $\left(\mathrm{q}_{\exp }=128.72 \mathrm{mg} \mathrm{g}^{-1} ; \mathrm{q}_{\text {pred }}=\right.$ $130.80 \mathrm{mg} \mathrm{g}^{-1}$ ). The porous material showed high efficiency against a synthetic mixture containing various drugs and salts, removing $86.79 \%$. Therefore, the activated carbon sample obtained from jabuticaba (Plinia cauliflora) fruit peels may be employed as an alternative adsorbent to treat wastewater-containing drugs effectively.
\end{abstract}

Keywords

Grapetree peel, Plinia cauliflora, Activated carbon, Naproxen, Adsorption 